\title{
A New Arterial Cannulation Technique: Arterial Cannulation through Aortic Anastomosis (“Kaplan” Technique)
}

\author{
Mehmet Kaplan, MD, Anil Karaagac, MD, Mehmet Inanç Yesilkaya, MD, Tolga Can, MD, \\ Yusuf Kagan Pocan, MD, Hakki Aydogan, MD \\ Department of Cardiovascular Surgery, Siyami Ersek Thoracic and Cardiovascular Surgery Training and Research Hospital, \\ University of Health Sciences, Istanbul, Turkey
}

\section{ABSTRACT}

We performed Bentall procedure on a 65-year-old male patient. Cardiopulmonary bypass was initiated via cannulation of the aneurysmatic segment of the aorta. Distal anastomosis was performed with the open technique under deep hypothermic circulatory arrest at $18^{\circ} \mathrm{C}$.

We performed arterial recannulation through the anastomosis with a new technique, and cardiopulmonary bypass was reestablished. Cardiopulmonary bypass was terminated after rewarming and de-airing phases, and decannulation was performed without any problems.

By this technique, the patient had no additional incisions for arterial cannulation, and there were no additional cannulation sutures left on the patient's arterial tree or the valved conduit.

\section{INTRODUCTION}

Various arteries (axillary and femoral arteries, brachiocephalic trunk, distal ascending aorta) are preferred for arterial cannulation in ascending aortic and aortic root aneurysm operations [Strauch 2004; Svensson 2004; Preventza 2015].

We prefer cannulating the aneurysmatic segment directly through only one sternotomy incision in our routine practice. After reconstructing the aortic root, we perform the distal anastomosis with the open technique under deep hypothermic circulatory arrest (DHCA) at $18^{\circ} \mathrm{C}$ without cerebral perfusion. Thus far we have used one-branched grafts for ascending aortic replacements and recannulated the branch, and we have used valved conduits for aortic root reconstructions with recannulating the conduit itself for cardiopulmonary bypass (CPB) [Kaplan 2015].

In this case, we identified a new arterial cannulation technique. We have performed the arterial recannulation through distal conduit-aorta anastomosis after DHCA.

Received October 31, 2018; received in revised form November 20, 2018; accepted November 23, 2018.

Correspondence: Prof. Mehmet Kaplan, MD, Atatürk Mah, SedefCad, Mercan 11. Blok, D: 38, 34758 Atasehir, Istanbul, Turkey; +90-532-270-36-33; fax: +90-216-337-97-19 (e-mail: drmehmetkaplan@gmail.com).

\section{CASE}

Operative Technique

We have performed Bentall procedure for a 65 -year-old male patient with ascending aortic and aortic root aneurysms (58 and $54 \mathrm{~mm}$, respectively) and severe aortic regurgitation. $\mathrm{CPB}$ was initiated after distal ascending aortic arterial (arterial cannula, $24 \mathrm{Fr}$, Andocor, Zoersel, Belgium) and right atrial venous cannulations (Figure 1A).

The aortic valve and aortic root were resected and replaced with a 27/30-mm valved conduit (Medtronic Open Pivot Aortic Valved Graft, Medtronic, Minneapolis, MN, USA) at $28^{\circ} \mathrm{C}$. We continued cooling the patient while performing coronary reimplantations and established DHCA at $18^{\circ} \mathrm{C}$ for distal anastomosis. We did not use cerebral perfusion while performing the distal anastomosis and monitored cerebral oxygenation with near-infrared spectroscopy (NIRS) throughout the operation.

We removed the arterial cannula and resected the aneurysmatic ascending aorta up to the origin of the innominate artery. Then we started performing the distal anastomosis with running 3/0-25 propylene sutures (Propilen, Doğsan, Istanbul, Turkey) and supported the tissue with a polytetrafluoroethylene (PTFE) felt (PTFE, Venaporta, Yenisehir, Ankara, Turkey). After finishing the posterior one third of the anastomosis, we added 3 extra pledgeted 4/0-25 propylene sutures (Propilen, Doğsan) with small pledgets on the interior side to prevent anastomotic leakage from the posterior side. Afterwards we proceeded with the running sutures on both sides of the anastomosis until a small gap was left for arterial cannulation. We added 2 pledgeted 4/0-25 propylene sutures on both sides of the gap to stabilize the anastomosis and to prevent the expanding of the gap and tied them with running 3/0-25 propylene sutures. Then running 3/0-25 propylene sutures were continued, directed from the graft to the aortic tissue over the gap and left untied. An extra 4/0-25 propylene suture directed from the aorta to the graft was also added on the cannulation site.

After starting the arterial flow, we filled and de-aired the arterial lumen and inserted a root cannula ( $7 \mathrm{Fr}$, Medtronic) on the conduit for cardioplegia perfusion and extra de-airing. Finally we inserted the arterial cannula through the gap on the anastomosis, the running $3 / 0-25$ propylene sutures and extra 4/0-25 propylene suture were snared over the cannula, and $\mathrm{CPB}$ was initiated ("Kaplan" technique) (Figure 1B). DHCA time was 23 minutes. 
The conduit was cross-clamped and we started to rewarm the patient. The heat gradient between the patient's blood and the heat exchanger was $3^{\circ} \mathrm{C}$ until the patient's temperature
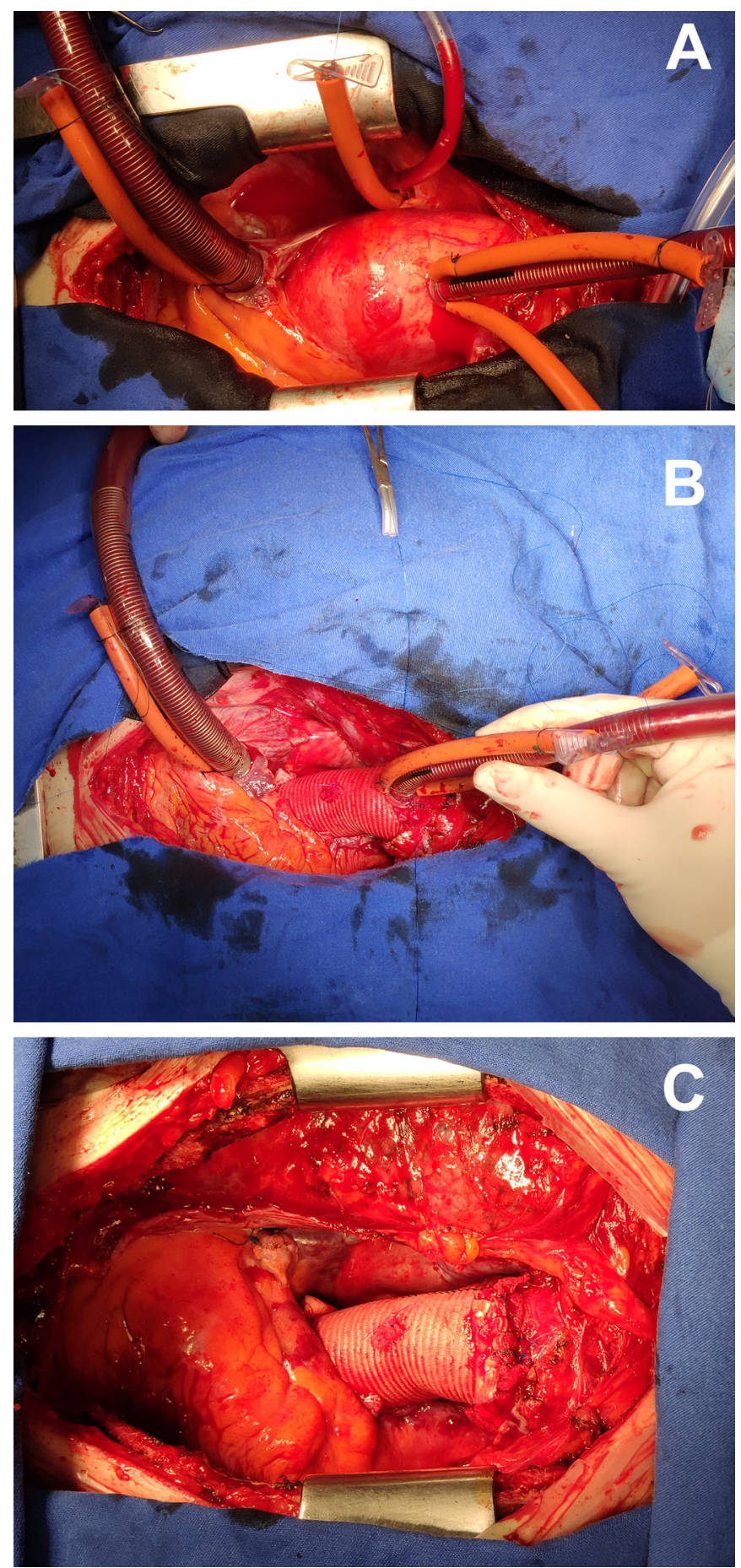

Figure (A), Arterial cannulation of the aneurysmatic ascending aorta. (B), Arterial cannulation through the anastomosis between the valved conduit and the distal aorta after deep hypothermic circulatory arrest (DHCA). (C), Image of the anastomosis between valved conduit and the distal aorta after decannulation. was $24^{\circ} \mathrm{C}, 5^{\circ} \mathrm{C}$ until the patient's temperature was $32^{\circ} \mathrm{C}$, and a maximum $8^{\circ} \mathrm{C}$ until the patient was fully rewarmed $\left(37.6^{\circ} \mathrm{C}\right)$. The temperature of the heat exchanger never exceeded $40^{\circ} \mathrm{C}$. Antegrade cardioplegia was delivered 2 more times per 20 minutes. After the heart started beating at $28^{\circ} \mathrm{C}$, we removed the cross-clamp. CPB was terminated after the patient was fully rewarmed and hemodynamically stable. We tied the running $3 / 0-25$ propylene sutures after removing the arterial cannula and used the previously added extra two 4/0-25 propylene sutures with a small PTFE felt to support the arterial cannulation site on the anastomosis (Figure 1C). We did not experience any problem by means of anastomotic security and arterial flow through the anastomotic cannula. Afterwards, the operation was ended in a routine fashion.

\section{Postoperative Course}

The patient was awake at the postoperative fourth hour with no neurological dysfunction. He was extubated at the postoperative 19th hour and transferred to the ward at postoperative day 2 at the 41 st hour. He was not transfused with any blood or blood products. He recovered uneventfully and was discharged at postoperative day 8 .

\section{DISCUSSION}

Axillary, femoral, and innominate arteries and distal ascending aorta are widely used cannulation sites in common practice while performing surgical reconstruction with crossclamping the distal ascending aorta [Strauch 2004; Svensson 2004; Preventza2015]. We have performed the arterial cannulation through the aneurysmatic aortic segment on 70 patients with ascending aortic and aortic root aneurysms up to today. We performed the distal anastomosis with the open technique without cross-clamping under DHCA at $18^{\circ} \mathrm{C}$.

There are quite a few studies favoring only DHCA to be sufficient during the using of the open distal anastomosis technique; however, some are recommending using cerebral perfusion alongside DHCA in these cases [Gega 2007; Khaladj 2008; Ziganshin 2014; Kaplan 2015]. Thus far, we have been able to perform the technique under 30 minutes under DHCA in all of our cases. We also think deep hypothermia under 30 minutes is sufficient for cerebral protection; this is parallel to what is in the literature.

We resect, under DHCA, the aneurysmatic ascending aorta as much as we can up to the origin of the brachiocephalic trunk. By this method, we achieve maximal resection of the aneurysmatic aortic tissue. The patients do not have extra incisions for arterial cannulation other than a sternotomy incision, and there are no suture lines left on the patients' arterial tree.

We aimed to perform open heart surgery without blood and blood product transfusion as we also did for this patient. We placed the CPB lines on the left side of the operating surgeon and then removed unnecessary lines (approximately 1 meter) from the circuit. By this way, the prime solution of the CPB circuit was decreased from $1200 \mathrm{~mL}$ to $700-750$ $\mathrm{mL}$. We always base our decision of transfusion not only on 
hemoglobin values but also on the hemodynamic and clinical parameters of our patients [Kaplan 2017]. By this method, we did not use any blood or blood products also for this patient.

We have used one-branched grafts for ascending aortic replacement, recannulating through the branch and valved conduits for aortic root reconstructions by recannulating the conduit itself for arterial perfusion. In our 71st case, we performed the arterial recannulation through the distal anastomosis to reinitiate CPB after DHCA and have not experienced any problems. We have not find any data for arterial cannulation through the aortic anastomosis in the literature.

With this case; we identify a new arterial cannulation technique ("Kaplan" technique) which is simple, safe, and useful. This method can be used to have graft integrity and when there are no branched grafts for economical reasons. We aim to prevent potential bleeding from the cannulation site on the valved conduit by using this technique. We intend to use this technique in all of our ascending aortic and aortic root aneurysm cases from now on.

\section{REFERENCES}

Gega A, Rizzo JA, Johnson MH, Tranquilli M, Farkas EA, Elefteriades JA. 2007. Straight deep hypothermic arrest: experience in 394 patients supports its effectiveness as a sole means of brain preservation. Ann Thorac Surg 84(3):759-66; discussion 766-7.

Kaplan M, Can T, Karaagac A, et al. 2017. Open cardiac surgery without blood and blood products transplantation. Heart Surg Forum 20(6):E239-46.

Kaplan M, Temur B, Can T, Abay G, Olsun A, Aydogan H. 2015. Open distal anastomosis technique for ascending aortic aneurysm repair without cerebral perfusion. Heart Surg Forum 18(4):E124-8.

Khaladj N, Shrestha M, Meck S, et al. 2008. Hypothermic circulatory arrest with selective antegrade cerebral perfusion in ascending aortic and aortic arch surgery: a risk factor analysis for adverse outcome in 501 patients. J Thorac Cardiovasc Surg 135(4):908-14.

Preventza O, Garcia A, Tuluca A, et al. 2015. Innominate artery cannulation for proximal aortic surgery: outcomes and neurological events in 263 patients. Eur J Cardiothorac Surg 48(6):937-42; discussion 942.

Strauch JT, Spielvogel D, Lauten A, et al. 2004. Axillary artery cannulation: routine use in ascending aorta and aortic arch replacement. Ann Thorac Surg 78(1):103-8; discussion 108.

Svensson LG, Blackstone EH, Rajeswaran J, et al. 2004. Does the arterial cannulation site for circulatory arrest influence stroke risk? Ann Thorac Surg 78(4);1274-84; discussion 1274-84.

Ziganshin BA, Rajbanshi BG, Tranquilli M, Fang H, Rizzo JA, Elefteriades JA. 2014. Straight deep hypothermic circulatory arrest for cerebral protection during aortic arch surgery: safe and effective. J Thorac Cardiovasc Surg 148(3):888-98; discussion 898-900. 